\title{
Ocular Biometry in Patients with Primary Open Angle Glaucoma (POAG)
}

\section{Vijaya Pai* and Rohith Simha Thota}

Department of Ophthalmology, Kasturba Medical College, Manipal University, India

*Corresponding author: Vijaya Pai, Professor, Department of Ophthalmology, Kasturba Medical College, Manipal University, India, Tel: 09845426427; E-mail: paivijaya@yahoo.co.in

Received date: November 26, 2016; Accepted date: January 29, 2017; Published date: January 29, 2017

Copyright: (c) 2017 Pai V, et al. This is an open-access article distributed under the terms of the Creative Commons Attribution License, which permits unrestricted use, distribution, and reproduction in any medium, provided the original author and source are credited.

\begin{abstract}
Purpose: To compare ocular biometry in patients with POAG (Primary open angle glaucoma) and age-matched controls.

Methodology: Cross sectional epidemiological study at a tertiary care center between October 2014 to August 2016. Patients with POAG formed the study group. Control group included those patients who did not have glaucoma and who were posted for the cataract surgery. Axial length $(A L)$ was measured using Ultrasound $A$ scan (TOPCON KR8900) by immersion technique and keratometry 'K' value measured using auto refractokeratometry [ALCON orbscan]. Statistical analysis was done using student 't' test.
\end{abstract}

Results: 212 eyes of 140 patients were included in the study. There were 106 eyes in each group. Age of the patients varied from $50-90$ years in the study group and 48-79 years in the control group. AL in POAG (23.88 mm \pm $0.19)$ was significantly higher $(p<0.0000)$ than age-matched controls $(22.0 \mathrm{~mm} \pm 0.10)$. K value in POAG (44.29 D \pm $0.19)$ was significantly lower $(p<0.0001)$ than age-matched controls $(45.38 \mathrm{D} \pm 0.14)$.

Conclusion: Patients with POAG seem to have longer AL and flatter corneas when compared to age-matched controls.

Keywords: Biometry; Keratometry; POAG

\section{Introduction}

Glaucoma is the leading cause of blindness all over the world after cataract blindness. In 2010, worldwide 60.5 million people were expected to have OAG (Open angle glaucoma) and ACG (Angle closure glaucoma), increasing to 79.6 million by 2020 , and of these, $74 \%$ will have OAG1. Asians represent $47 \%$ of those with all glaucoma and $87 \%$ of those with ACG1. 4.5 million people with OAG and 3.9 million people with ACG were expected to have bilateral blindness in 2010 , rising to 5.9 and 5.3 million people in 2020 , respectively [1].

There are approximately 11.2 million persons aged 40 years and older with glaucoma in India. Primary open angle glaucoma is estimated to affect 6.48 million persons. The estimated number with primary angle-closure glaucoma is 2.54 million. Those with any form of primary angle-closure disease could comprise 27.6 million persons [2].

Many risk factors (high IOP, thin central corneal thickness, increasing age, male gender, black race, family history, adult onset diabetes, migraine and peripheral vasospasm, alcohol consumption, cigarette smoking) have been identified for POAG, but only a small number is well supported by evidence. Elevated IOP remains the most prominent factor. Myopia is considered as a risk factor for POAG [3-5]. In our study we compared the axial length $(\mathrm{AL})$ and ' $\mathrm{K}$ ' value in patients with POAG to the age matched controls.

\section{Methods}

This was a cross sectional epidemiological study of patients diagnosed with POAG and age matched patients posted for cataract surgery in our hospital, during the period October 2014 to August 2016. The diagnosis of POAG was based on the evidence of optic nerve damage (optic disc or retinal nerve fiber layer structural abnormalities, reliable and reproducible visual field abnormality representing functional status), adult onset, open anterior chamber angles, absence of other known explanations for progressive glaucomatous optic nerve damage6.The study was conducted in accordance with the declaration of Helsinki, after clearence from the Institutional ethical committee. Patients aged above 40 years with POAG formed the study group and patients posted for cataract surgery without POAG formed the control group. These patients were explained about the study and a written informed consent was obtained from those willing to participate in the study. Patient with Normal tension glaucoma, Ocular hypertension and secondary glaucoma's were excluded from the study.

The basic demographic profile including age, sex, were documented. A history of systemic conditions including diabetes mellitus, hypertension and medications were noted. All the patients underwent a detailed ophthalmic evaluation.IOP was measured using a GoldmannApplanation Tonometer. Gonioscopy was done using Goldmann single mirror goniolens. After pupillary dilatation, the optic disc was evaluated with the slit lamp (Model HAAG STREIT SLIT LAMP BM 900) using +90 D lens. Axial length (AL) was measured using Ultrasound A scan by immersion technique (ALCON orbscan) and ' $\mathrm{K}$ ' value measured using auto refracto-keratometry (Model TOPCON KR8900). The data obtained was entered Microsoft excel 
spread sheet and data was analysed. Student ' $t$ ' test was used to assess the statistical significance

\section{Results}

A total of 212 eyes of 140 patients were included in the study. There were 70 cases (106 eyes) and 70 age-matched controls (106 eyes). Among the study group 43 patients (61.4\%) were males and 27 patients (38.6\%) were females. Among controls 37 patients (52.8\%) were males and 33 patients $(47.2 \%)$ were females.

Mean age of the patients was $69.72 \pm 7.83$ years, ranging from 50 to 90 years in study group and Mean age of patients was $64.78 \pm 6.94$ years, ranging from 48 to 79 years in controls.

In the study group, AL ranged from $21.52 \mathrm{~mm}$ to $27.61 \mathrm{~mm}$ and mean $\mathrm{AL}$ was $23.35 \pm 0.98 \mathrm{~mm}$. In the control group, $\mathrm{AL}$ ranged from $20.1 \mathrm{~mm}$ to $24.04 \mathrm{~mm}$ and mean AL was $21.29 \pm 0.92 \mathrm{~mm}$. AL in POAG $(23.35 \pm 0.98 \mathrm{~mm})$ was significantly higher $(\mathrm{p}<0.0000)$ than age-matched controls $(21.29 \pm 0.92 \mathrm{~mm})$.

$\mathrm{K}$ value was calculated by using Average of $\mathrm{K} 1$ and $\mathrm{K} 2$. In the study group, mean $\mathrm{K}$ value was $44.13 \pm 1.8 \mathrm{D}$. In the control group, mean $\mathrm{K}$ value was $45.10 \pm 1.1 \mathrm{D}$. $\mathrm{K}$ value in POAG $(44.13 \pm 1.8 \mathrm{D})$ was significantly lower $(\mathrm{p}<0.0000)$ than age-matched controls $(45.10 \pm 1.1$ D).

\section{Discussion}

There is evidence in literature that myopia is one of the risk factor for POAG, which has been proven in several clinical trials and in several population based studies (The Blue Mountain Eye Study [3], The Beaver Dam Eye Study [4], The Beijing Eye Study [5], The Barbados Eye Study [6], The Aravind Comprehensive Eye Study[7], The Tajimi Eye Study [8]. However, very few studies have demonstrated an association between increasing AL and POAG.

In our study, we found $\mathrm{AL}$ in POAG patients was significantly higher $(\mathrm{p}<0.0000)$ than age - matched patients.

The Singapore Malay Eye Study [9] (SMES) conducted by Shamira A Perera et al. in Malay population of Singapore, demonstrated an association between increasing AL and POAG, thus suggesting axial myopia as a potential risk factor for POAG.

The Meiktila Eye Study in Burmese population by Casson RJ et al. showed an association between long AL and POAG in univariate analysis [10].

Congdon et al. [11] conducted a study in POAG and POAG suspect and found that long AL, low corneal hysteresis was associated with progressive field worsening and thin central corneal thickness was associated with glaucoma damage. An association between long AL and high IOP was also found.

Tomlinson et al. [12] showed that long AL eyes had high IOP values. They also found that males had significant high IOP and AL than females. In our study, we found AL in POAG patients was significantly higher than age matched controls and no significant difference between males and females.

Very few studies have studied the relationship between corneal curvature and POAG. Relationship between POAG and corneal curvature is inconclusive.
The Los Angeles Latino Eye Study (LALES) [13], population based study conducted by Kuzen et al. in Latino's of La Puente city of California showed:

-Prevalence of OAG was $26 \%$ high for each millimeter-long AL and prevalence of $\mathrm{OAG}$ increases exponentially for $\mathrm{AL}>25$ millimeter.

-Prevalence of OAG was $15 \%$ high for each diopter decrease of corneal power after adjusting the covariates.

The Tajimi Eye Study [8] conducted by Yasuyuki Suzuki in Japanese population showed no association between corneal curvature and glaucoma.

Francis et al. [14] conducted a study on Effects of Corneal Thickness, Corneal Curvature, and Intraocular Pressure Level on Goldmann Applanation Tonometry (GAT) and Dynamic Contour Tonometry (DCT) and found that mean DCT IOP increased with increasing corneal curvature and IOP measured by GAT did not show any association.

Kohlhaas et al. [15] showed no correlation between intraocular pressure and corneal curvature at $20 \mathrm{mmHg}, 35 \mathrm{mmHg}, 50 \mathrm{mmHg}$. They also showed no correlation between axial length and intraocular pressure at $20 \mathrm{mmHg}, 35 \mathrm{mmHg}, 50 \mathrm{mmHg}$. Both were not statistically significant.

Saleh et al. [16] also conducted a study on the effect of corneal curvature on intraocular pressure measurement by Goldmann applanation tonometer and ocular blood flow pneumotonometer and found no correlation between intraocular pressure and corneal curvature by either technique.

Kaufmann et al. [17] showed no correlation between corneal curvature and IOP with Dynamic contour tonometer and Goldmann applanation tonometer.

Matsumoto et al. [18 ] studied the influence of corneal thickness and corneal curvature on IOP with non-contact tonometer and Goldmann applanation tonometer in Japanese population and found that correlation between corneal curvature and IOP was not statistically significant.

Rask et al. found no correlation between corneal curvature and IOP measured using Goldmann applanation tonometer [19].

Mark et al. [20] showed that 3 diopter increases in corneal curvature caused a $1 \mathrm{mmHg}$ rise in GAT value. Watkins et al. [21] conducted a study on the influence on corneal curvature on intraocular pressure with Goldmann applanation tonometer and ocular blood flow pneumotonometer and found both techniques showed higher IOP with steeper cornea, but was not statistically significant.

Harada et al. conducted a study on influence of corneal curvature radius on intraocular pressure measurement using non-contact tonometer and Goldman applanation tonometer and found negative correlation with Goldmann applanation tonometer and no correlation with non-contact tonometer [22].

Gunvant et al. [23] studied the effect of corneal parameters on measurments using the pulsatile ocular blood flow tonograph and GAT and found that per $1 \mathrm{~mm}$ increase in mean corneal curvature, there were $1.14 \mathrm{mmHg}$ increases in IOP with GAT and $2.6 \mathrm{mmHg}$ increases in IOP with pulsatile ocular blood flow tonograph.

In the above studies, few have shown no correlation between corneal curvature and IOP, few showed flatter cornea's have high IOP 
[13] and few showed steeper cornea's have high IOP [20,21,]. In our study we observed that POAG patients had flatter corneas as compared to the age matched controls.

In conclusion in our study we observed that $\mathrm{AL}$ in POAG patients was significantly higher than age-matched controls and $\mathrm{K}$ value in POAG was significantly lower than age-matched controls. More population based studies are needed to decide conclusivey about Flat $\mathrm{K}$ as one of the risk factor for POAG.

\section{References}

1. Quigley HA, Broman AT (2006) The number of people with glaucoma worldwide in 2010 and 2020. Br J Ophthalmol 90: 262-267.

2. George R, Ve RS, Vijaya L (2010) Glaucoma in India: estimated burden of disease. J Glaucoma 19: 391-397.

3. Mitchell P, Hourihan F, Sandbach J, Wang JJ (1999) The relationship between glaucoma and myopia: the Blue Mountains Eye Study. Ophthalmology 106: 2010-2015.

4. Wong TY, Klein BE, Klein R, Knudtson M, Lee KE (2003) Refractive errors, intraocular pressure, and glaucoma in a white population. Ophthalmology 110: 211-217.

5. Xu L, Wang Y, Wang S, Wang Y, Jonas JB (2007) High myopia and glaucoma susceptibility the Beijing Eye Study. Ophthalmol 114: 216-220.

6. Wu SY, Nemesure B, Leske MC (1999) Refractive errors in a black adult population: the Barbados Eye Study. Invest Ophthalmol Vis Sci 40: 2179-2184.

7. Ramakrishnan R, Nirmalan PK, Krishnadas R, Thulasiraj RD, Tielsch JM, et al.(2003) Glaucoma in a rural population of southern India: the Aravind comprehensive eye survey. Ophthalmology 110:1484-1490.

8. Suzuki Y, Iwase A, Araie M, Yamamoto T, Abe H, et al. (2006) Risk factors for open-angle glaucoma in a Japanese population: the Tajimi Study. Ophthalmology 13: 1613-1617.

9. Perera SA, Wong TY, Tay WT, Foster PJ, Saw SM, et al. (2010) Refractive error, axial dimensions, and primary open-angle glaucoma: the Singapore Malay Eye Study. Arch Ophthalmol 128: 900-905.

10. Casson RJ, Gupta A, Newland HS, McGovern S, Muecke J, et al. (2007) Risk factors for primary open-angle glaucoma in a Burmese population: the Meiktila Eye Study. Clin Exp Ophthalmol 35: 739-744.

11. Congdon NG, Broman AT, Bandeen-Roche K, Grover D, Quigley HA (2006) Central corneal thickness and corneal hysteresis associated with glaucoma damage. Am J Ophthalmol 141: 868 -875.
12. Tomlinson A, Phillips CI (1970) Applanation tension and axial length of the eyeball. Br J Ophthalmol 54: 548-553.

13. Kuzin AA, Varma R, Reddy HS, Torres M, Azen SP, et al. (2010) Ocular biometry and open-angle glaucoma: the Los Angeles Latino Eye Study. Ophthalmology 117: 1713-1719.

14. Francis BA, Hsieh A, Lai MY, Chopra V, Pena F, et al. (2007) Effects of corneal thickness, corneal curvature, and intraocular pressure level on Goldmann applanation tonometry and dynamic contour tonometry. Ophthalmology 114: 20-26.

15. Kohlhaas M, Boehm AG, Spoerl E, Pürsten A, Grein HJ, et al. (2006) Effect of central corneal thickness, corneal curvature, and axial length on applanation tonometry. Arch Ophthalmol 124: 471-476.

16. Saleh TA, Adams M, McDermott B, Claridge KG, Ewings P (2006) Effects of central corneal thickness and corneal curvature on the intraocular pressure measurement by Goldmann applanation tonometer and ocular blood flow pneumatonometer. Clin Exp Ophthalmol 34: 516-520.

17. Kaufmann C, Bachmann LM, Thiel MA (2004) Comparison of dynamic contour tonometry with Goldmann applanation tonometry. Invest Ophthalmol Vis Sci 45: 3118-3121.

18. Matsumoto T, Makino H, Uozato H, Saishin M, Miyamoto S (2000) The Influence of Corneal Thickness and Curvature on the Difference Between Intraocular Pressure Measurements Obtained with a Non-contact Tonometer and Those with a Goldmann Applanation Tonometer. Jpn J Ophthalmol 44: 691

19. Rask G, Behndig A (2006) Effects of corneal thickness, curvature, astigmatism and direction of gaze on Goldmann applanation tonometry readings. Ophthalmic Res 38: 49-55.

20. Mark HH (1973) Corneal curvature in applanation tonometry. Am J Ophthalmol 76: 223-224.

21. Watkins RJ, Gunvant P, Uddin J, Broadway D (2002) The Influence of Central Corneal Thickness \& Corneal Curvature on Intraocular Pressure Measurement with the Goldmann Tonometer \& the POBF Pneumotonometer. Invest Ophthalmol Vis Sci 43: 3413.

22. Harada Y, Hirose N, Kubota T, Tawara A (2008) The Influence of Central Corneal Thickness and Corneal Curvature Radius on The Intraocular Pressure as Measured By Different Tonometers: Noncontact and Goldmann Applanation Tonometers. J Glaucoma 17: 619-625.

23. Gunvant P, Baskaran M, Vijaya L, Joseph IS, Watkins RJ, et al. (2004) Effect of corneal parameters on measurements using the pulsatile ocular blood flow tonograph and Goldmann applanation tonometer. Br J Ophthalmol 88: 518-522. 